\title{
CONTRIBUIÇÃO DO SISTEMA RADICULAR DE MUDAS MICROPROPAGADAS NA ABSORÇÃO DE NITROGÊNIO DE ABACAXIZEIRO CULTIVAR VITÓRIA ${ }^{1}$
}

\author{
DANÚBIA GONÇALVES RIBEIRO², MARCO ANTÔNIO DA SILVA VASCONCELLOS², \\ ADELSON PAULO ARAÚJO
}

RESUMO - Este trabalho objetivou avaliar a contribuição das raízes pré-formadas de mudas micropropagadas de abacaxizeiro cultivar Vitória no crescimento e absorção de nitrogênio $(\mathrm{N})$, nos primeiros meses de crescimento. Mudas micropropagadas permaneceram 75 dias em substrato em casa de vegetação, quando foram transplantadas para vasos com $5 \mathrm{~kg}$ de solo. Foi adotado um esquema fatorial incompleto, com cinco repetições, com três tratamentos de poda do sistema radicular (sem poda, meia-poda e poda total), quatro épocas de aplicação de N (no transplante, aos 30; 60 e 90 dias após transplante - DAT) e quatro épocas de coleta das plantas (aos 30; 60; 90 e 120 DAT). Nas coletas, foram mensuradas a massa seca e a acumulação de $\mathrm{N}$ na parte aérea e raiz. A área radicular foi determinada por análise digital de imagens, e o influxo de $\mathrm{N}$ nas raízes, estimado pela análise de crescimento vegetal. As plantas sem poda de raiz apresentaram maior massa de parte aérea, massa de raiz, área radicular e acumulação de $\mathrm{N}$, que as plantas com poda total, em todas as épocas de avaliação. A aplicação de N no transplante ou aos 30 DAT proporcionou maior crescimento da parte aérea ao final do experimento. A época de aplicação de $\mathrm{N}$ não afetou a massa radicular e a acumulação de $\mathrm{N}$, mas as plantas que receberam $\mathrm{N}$ no transplante tiveram maior área radicular aos 120 DAT. As plantas com poda total apresentaram maior influxo radicular de N, compensando parcialmente sua menor área radicular. Conclui-se que a poda total ou parcial das raízes no momento do transplante das mudas micropropagadas reduziu o crescimento e a acumulação de $\mathrm{N}$ da parte aérea do abacaxizeiro, e que a aplicação de $\mathrm{N}$ no transplante proporcionou maior crescimento da parte aérea do que a aplicação tardia de N. Termos para indexação: abacaxi, Ananas comosus, análise de crescimento vegetal, raiz.

\section{ROOT SYSTEM CONTRIBUTION OF MIPROPROPAGATED SEEDLINGS ON NITROGEN ABSORPTION OF PINEAPPLE PLANT CULTIVAR VITORIA}

\begin{abstract}
This study intended to evaluate the contribution of the preformed roots of pineapple micropropagated seedlings cultivar Vitoria on plant growth and nitrogen $(\mathrm{N})$ absorption in the first months of growth. Micropropagated seedlings stayed 75 days in a substrate in greenhouse, when they were transplanted to pots with $5 \mathrm{~kg}$ of soil. An incomplete factorial design with five replicates was applied, with three treatments of root pruning (without pruning, half pruning and total pruning), four times of $\mathrm{N}$ application (at transplanting, 30, 60 and 90 days after transplant - DAT), and four dates of plant harvest (30, 60, 90 and 120 DAT). In the samplings, dry matter and $\mathrm{N}$ accumulation in shoot and root were measured. Root area was determined by digital image analysis, and influx of $\mathrm{N}$ into roots was estimated by plant growth analysis. Plants without root pruning presented higher shoot mass, root mass, root area and $\mathrm{N}$ accumulation than plants with total root pruning, at every harvest. Application of $\mathrm{N}$ at transplanting or 30 DAT provided higher shoot growth at the end of the experiment. Time of $\mathrm{N}$ application did not affect root mass and $\mathrm{N}$ accumulation, but plants receiving $\mathrm{N}$ at transplanting had higher root area at 120 DAT. Plants with total root pruning showed higher influx of $\mathrm{N}$ into roots, compensating partially their lower root area. It is concluded that the partial or total root pruning at transplanting of micropropagated seedlings reduced the growth and $\mathrm{N}$ accumulation of pineapple plant, and that the $\mathrm{N}$ application at transplanting provided higher shoot growth than late $\mathrm{N}$ application. Index terms: pineapple, Ananas comosus, plant growth analysis, root.
\end{abstract}

\footnotetext{
1'(Trabalho 005-11). Recebido em: 04-01-20111. Aceito para publicação em: 08-07-2011. Parte da Dissertação de Mestrado em Fitotecnia do primeiro autor apresentada à UFRRJ. Bolsista CAPES.

2Departamento de Fitotecnia, UFRRJ, BR 465 km 7. Seropédica - RJ. Email: masv@ufrrj.br

${ }^{3}$ Departamento de Solos, UFRRJ, BR 465 km 7. Seropédica - RJ. Email: aparaujo@ufrrj.br
} 


\section{INTRODUÇÃO}

O abacaxi [Ananas comosus (L.) Merrill] é uma das fruteiras mais cultivadas no Brasil. A quantidade produzida de abacaxi no Brasil duplicou entre 1990 e 2008, variando de 736 para 1.712 milhões de frutos, em consequência principalmente do aumento de $99 \%$ na área colhida, pois o rendimento médio aumentou apenas de 22,2 para 26,0 mil frutos ha $^{-1}$ neste período (IBGE, 2010). As duas cultivares que predominam nos cultivos de abacaxi no Brasil, Pérola e Smooth Cayenne, são suscetíveis à fusariose, doença causada pelo fungo Fusarium subglutinans que causa sérios danos à produção (CUNHA et al., 2007). Programas de melhoramento genético têm obtido híbridos com características comerciais favoráveis e resistentes à fusariose, e que têm sido lançados como novas cultivares (CUNHA et al., 2007). Em 2006, foi lançada a cultivar Vitória, desenvolvida pela Embrapa Mandioca e Fruticultura, que se destaca por apresentar, além de resistência à fusariose, ausência de espinhos nas folhas, bom crescimento e produtividade, e frutos com aptidão para consumo in natura e para industrialização (VENTURA et al., 2006).

Os plantios comerciais de abacaxi no Brasil são feitos, em sua grande maioria, com mudas convencionais, que originaram $96,0 \%$ da produção nacional em 2006, com apenas 3,6\% da produção oriunda de mudas certificadas (IBGE, 2009). A multiplicação assexuada do abacaxi se faz por meio de filhotes, filhotes-rebentões ou rebentos, que são brotações que surgem, respectivamente, do pedúnculo, na região de inserção do pedúnculo no caule, e na região basal do caule, ou ainda por meio de mudas originárias da coroa do fruto (CUNHA; REINHARDT, 2004). A multiplicação por micropropagação, através de cultura de tecidos in vitro, permite a obtenção de mudas livres de doenças por meio da limpeza clonal, fornecendo um grande número de plantas sadias e de qualidade em um curto período de tempo e em um pequeno espaço físico (GUERRA et al., 1999). Além disto, a micropropagação permite uma fixação mais rápida de ganhos genéticos nas populações clonais, reduzindo o tempo de lançamento de novas cultivares (GUERRA et al., 1999).

$\mathrm{O}$ abacaxizeiro é uma planta muito exigente em nutrientes, e seu estado nutricional tem grande influência no desenvolvimento vegetativo da planta, na produção e na qualidade do fruto (TEIXEIRA et al., 2002). A acumulação de $\mathrm{N}$ durante o ciclo de cultivo pode atingir $230 \mathrm{~kg} \mathrm{ha}^{-1}$, sendo cerca de $27 \%$ deste acúmulo exportado pela colheita do fruto
(SAN JOSÉ et al., 2007). A prática da adubação torna-se indispensável nos plantios comerciais, já que a maioria dos solos cultivados não consegue suprir integralmente as elevadas quantidades de nutrientes demandadas pela cultura (PAULA et al., 1991; VELOSO et al., 2001; SPIRONELLO et al., 2004). Em 2006, os plantios conduzidos com adubação química foram responsáveis por $80,7 \%$ da produção no Brasil, sendo o rendimento obtido nos cultivos com adubação química duas vezes superior ao rendimento dos cultivos sem adubação (IBGE, 2009).

O nitrogênio $(\mathrm{N})$ destaca-se como o segundo nutriente mais extraído pela cultura do abacaxizeiro, logo após do potássio (K) (PAULA et al., 1991). A adubação nitrogenada na cultura do abacaxi proporciona maior produção de frutos, frutos de maior tamanho, decréscimo na acidez do fruto e maior rendimento de suco (PAULA et al., 1991; VELOSO et al., 2001; TEIXEIRA et al., 2002; SPIRONELLO et al., 2004). As recomendações para a cultura preconizam que a adubação deve ser efetuada na fase vegetativa de seu ciclo, quando ocorrem as maiores taxas de acumulação pela planta, fracionando os fertilizantes nitrogenados e potássicos, em,- no máximo, três vezes, no período compreendido entre o plantio e os 30 dias que antecedem a indução floral (SOUZA, 2000; TEIXEIRA et al., 2002).

O sistema radicular do abacaxizeiro tem lento desenvolvimento, com grande concentração das raízes nas camadas superficiais do solo (INFORZATO et al., 1968). O crescimento do sistema radicular do abacaxizeiro foi contínuo em um período de 2 anos, mas a profundidade média do sistema radicular manteve-se sempre em $30 \mathrm{~cm}$ (SCHNEIDER et al., 1992). O restrito desenvolvimento do sistema radicular do abacaxizeiro está associado ao baixo consumo de água do cultivo, mas torna disponível apenas um limitado reservatório de água no solo, tornando a planta extremamente suscetível a déficits hídricos (EKERN, 1965). No abacaxi, predominam as raízes adventícias, que emergem do tecido vascular da região nodal do caule e já se apresentam parcialmente suberizadas (PY et al., 1987). Raízes primárias são encontradas apenas em mudas embrionárias, obtidas a partir da reprodução sexual (PY et al., 1987). As raízes mais velhas emergem da parte basal do caule e ramificam-se em um número limitado de raízes secundárias e terciárias, formando um sistema radicular fasciculado e fibroso, enquanto raízes mais novas emergem do caule entre as folhas vivas, crescendo em torno do caule sem ramificar-se, apresentando-se também bastante suberizadas (PY et al., 1987).

Há carência de informações científicas sobre a nutrição mineral das novas variedades recentemente 
lançadas e sobre a utilização de mudas micropropagadas de abacaxizeiro, pois as informações disponíveis na literatura sobre extração de nutrientes são referentes principalmente às cultivares Pérola e Smooth Cayenne, em cultivos a partir da utilização de mudasfilhotes ou rebentões. Por consequência, também são escassas as informações sobre o manejo das mudas micropropagadas durante a fase de viveiro e sua performance após o plantio no campo, assim como sobre a eficiência na absorção de nutrientes do sistema radicular presente nas mudas micropropagadas. Esta carência de informações tem levado os produtores a eliminar o sistema radicular de mudas micropropagadas, visando a facilitar o plantio; contudo, essa prática não é apoiada por resultados de pesquisas. Dessa forma, o presente trabalho teve como objetivo avaliar a contribuição das raízes pré-formadas em mudas micropropagadas, no crescimento e na absorção de $\mathrm{N}$ nos primeiros meses de crescimento de abacaxi cultivar Vitória.

\section{MATERIAL E MÉTODOS}

\section{Condições experimentais}

O experimento foi conduzido entre fevereiro e agosto de 2009, em casa de vegetação, no Departamento de Fitotecnia da Universidade Federal Rural do Rio de Janeiro, em Seropédica - RJ. As mudas da cultivar Vitória foram fornecidas pelo laboratório de cultura de tecidos Biomudas, de Venda Nova do Imigrante - ES. As mudas foram acondicionadas em sacos plásticos de 20 por 20 $\mathrm{cm}$, contendo o substrato Plantmax Hortaliças, permanecendo em casa de vegetação com telado nas laterais. Durante este período, as mudas receberam uma adubação foliar de solução com $5 \mathrm{~g} \mathrm{~L}^{-1}$ de ureia e $5 \mathrm{~g} \mathrm{~L}^{-1}$ de sulfato de potássio, equivalente a 20 $\mathrm{mg}$ de $\mathrm{N}$ e $20 \mathrm{mg}$ de $\mathrm{K}$ por planta, e irrigações por microaspersão uma a duas vezes por dia.

Após 75 dias, as mudas, que apresentavam em média 1,71 e $0,20 \mathrm{~g}$ de massa seca de parte aérea e raiz, respectivamente, foram transplantadas para vasos com $5 \mathrm{~kg}$ de solo. O solo utilizado foi o horizonte A de um Planossolo coletado na profundidade de 0 a $30 \mathrm{~cm}$, cuja caracterização apresentou (EMBRAPA, 1997): pH em água 6,8, 4,0 $\mathrm{cmol}_{\mathrm{c}} \mathrm{dm}^{-3}$ de Ca, 2,0 $\mathrm{cmol}_{\mathrm{c}} \mathrm{dm}^{-3}$ de $\mathrm{Mg}, 3,7$ cmol $\mathrm{dm}^{-3}$ de H, $0,0 \mathrm{cmol}_{\mathrm{c}} \mathrm{dm}^{-3} \mathrm{de} \mathrm{Al}, 5 \mathrm{mg} \mathrm{dm}^{-3} \mathrm{de}$ $\mathrm{P}$ disponível, $38 \mathrm{mg} \mathrm{dm}^{-3}$ de $\mathrm{K}$ disponível, textura francoarenosa. As doses de adubação recomendadas para a cultura (SOUZA, 2000) foram convertidas para cada planta considerando uma densidade de 40.000 plantas ha ${ }^{-1}$, e o solo de cada vaso recebeu $0,35 \mathrm{~g}$ de $\mathrm{P}$ e $0,62 \mathrm{~g}$ de $\mathrm{K}$, nas formas de $\mathrm{KH}_{2} \mathrm{PO}_{4}$ e $\mathrm{KCl}$, e foi homogeneizado.

O delineamento experimental foi o em blocos ao acaso, em esquema fatorial incompleto, com cinco repetições e uma planta por repetição, com três tratamentos de poda de raiz, quatro épocas de aplicação de $\mathrm{N}$ e quatro coletas de plantas em diferentes estádios. Os três tratamentos de poda de raiz consistiram em: sem poda (manutenção do sistema radicular pré-formado), meia-poda (eliminação das raízes a partir de $5 \mathrm{~cm}$ da base do sistema radicular) e poda total (eliminação de todo o sistema radicular pré-formado). As épocas de aplicação de $\mathrm{N}$ foram: no momento do transplante, aos 30 dias após o transplante (DAT), aos 60 DAT e aos 90 DAT. As coletas das plantas foram efetuadas aos 30; 60; 90 e 120 DAT. Adotou-se um esquema fatorial incompleto, pois dependendo da época de coleta não estavam presentes todos os tratamentos de época de adubação nitrogenada. Desta forma, na primeira coleta, efetuada aos $30 \mathrm{DAT}$, têm-se apenas os 3 tratamentos de poda do sistema radicular com adubação nitrogenada no transplante. Na coleta aos 60 DAT, tem-se um fatorial entre os 3 tratamentos de poda, e as épocas de aplicação de $\mathrm{N}$ no transplante e aos 30 DAT. Na coleta aos 90 DAT, tem-se um fatorial entre os 3 tratamentos de poda, e as épocas de aplicação de N no transplante, aos 30 e 60 DAT. Na coleta aos 120 DAT, tem-se um fatorial entre os 3 tratamentos de poda, e as quatro épocas de aplicação de N. Portanto, tem-se 10 diferentes combinações de épocas de aplicação de $\mathrm{N}$ com épocas de coleta, por sua vez combinados com 3 tratamentos de poda, com cinco repetições, totalizando 150 vasos no experimento.

Antes do transplante, as mudas foram padronizadas por tamanho, visando à uniformidade dentro de cada bloco experimental. Na instalação do experimento, foram conduzidos os três tratamentos de poda do sistema radicular, através de corte realizado com tesoura de poda. Quando da adubação nitrogenada, foi aplicado $0,6 \mathrm{~g}$ de $\mathrm{N}$ sobre o solo de cada vaso, na forma de $\left(\mathrm{NH}_{4}\right)_{2} \mathrm{SO}_{4}$ diluído em água. Os vasos recebiam água à medida que o solo se apresentava com pouca umidade, não excedendo a capacidade de campo do solo.

\section{Determinações}

Em cada coleta, a parte aérea e o sistema radicular foram separados, e as raízes foram lavadas. A parte aérea foi seca em estufa e pesada. As raízes de cada planta foram colocadas em frascos plásticos contendo solução de formaldeído a $2 \%$.

Para a digitalização, as raízes de todo o sistema radicular de cada planta foram espalhadas em folhas de acetato transparente, sendo, em 
média, necessária a montagem de três lâminas de acetato para cada planta. As folhas de acetato foram colocadas em scanner de mesa, e a imagem do sistema radicular digitalizada em tons de cinza (cinzento a 8 bits) com fundo preto e $300 \mathrm{dpi}$ de resolução (Figura 1). As imagens geradas foram convertidas em preto e branco, sendo eliminadas impurezas na imagem com o software Corel Photo Paint 12. A área e o comprimento radicular foram determinados com o programa Siarcs (Embrapa Instrumentação Agropecuária). Neste processo, é gerada uma imagem binária com as projeções dos segmentos radiculares, a partir da qual é mensurada a área radicular que, em seguida, é afinada para a mensuração do comprimento radicular (Figura 1).

Posteriormente, as raízes foram secas em estufa e pesadas. A área radicular específica foi obtida pela razão entre a área radicular e a massa seca de raízes, e a razão raiz:parte aérea, dividindose a massa da raiz pela massa da parte aérea. A parte aérea e o sistema radicular de cada planta foram moídos separadamente, sendo o teor de $\mathrm{N}$ determinado pelo método semi-micro Kjeldahl. A acumulação de $\mathrm{N}$ na parte aérea e raiz foi obtida pelo produto entre o teor de $\mathrm{N}$ e a massa seca respectiva.

$\mathrm{O}$ influxo radicular de $\mathrm{N}$, definido como a variação no conteúdo de $\mathrm{N}$ na planta por unidade de área radicular, por unidade de tempo (BARBER, 1984), foi estimado pelo método clássico de análise de crescimento, obtendo-se um valor médio de influxo para um intervalo de tempo entre duas coletas, através da fórmula (ARAÚJO, 2000):

$$
\operatorname{Inf}=\frac{1}{\mathrm{~A}} \cdot \frac{\mathrm{dU}}{\mathrm{dT}}=\frac{\mathrm{U}_{2}-\mathrm{U}_{1}}{\mathrm{~A}_{2}-\mathrm{A}_{1}} \cdot \frac{\ln \mathrm{A}_{2}-\ln \mathrm{A}_{1}}{\mathrm{~T}_{2}-\mathrm{T}_{1}}
$$

em que: Inf é o influxo de $\mathrm{N}$ por unidade de área radicular (em $\mathrm{mg} \mathrm{N} \mathrm{m}^{-2}$ dia $^{-1}$ ); $\mathrm{U}$ o conteúdo total de $\mathrm{N}$ na planta (em mg $\mathrm{N}$ planta $\left.{ }^{-1}\right)$; $\mathrm{A}$ a área radicular (em $\mathrm{m}^{2}$ planta $\left.^{-1}\right)$; $\mathrm{T}$ o tempo (em dias após transplante), e os subscritos 1 e 2 referem-se às épocas de coleta. De forma similar, foi calculado o influxo de $\mathrm{N}$ por unidade de comprimento radicular (em $\mu \mathrm{g} \mathrm{N} \mathrm{m}^{-1} \mathrm{dia}^{-1}$ ). Foi obtido um valor de influxo para cada tratamento e repetição experimental, para os intervalos 30-60 DAT, 60-90 DAT e 90-120 DAT.

Os dados obtidos foram submetidos à análise de variância, sendo avaliados os efeitos dos tratamentos de poda do sistema radicular, da época de aplicação do $\mathrm{N}$ e de suas interações, para cada época de coleta, isoladamente. Foi obtida a diferença mínima significativa entre médias, pelo teste de Tukey, a 5\% para apresentação nas figuras.

\section{RESULTADOS E DISCUSSÃO}

$\mathrm{Na}$ análise de variância dos caracteres avaliados, foram observados efeitos significativos dos tratamentos de poda do sistema radicular e das épocas de aplicação do adubo nitrogenado, mas, de forma geral, a interação entre estes fatores não foi significativa. Desta forma, são apresentados os efeitos isolados da poda do sistema radicular e das épocas de aplicação de $\mathrm{N}$ em cada época de coleta.

\section{Crescimento de parte aérea e raiz}

Em todas as épocas de avaliação, as plantas de abacaxi sem poda do sistema radicular apresentaram os maiores valores de massa seca de parte aérea, e as plantas com poda total, a menor massa de parte aérea (Figura 2). Aos 120 DAT, a massa de parte aérea das plantas que receberam poda total foi de $10,5 \mathrm{~g}$, enquanto das plantas sem poda foi de 13,3 $\mathrm{g}$ (Figura 2), ou seja, uma redução de $21 \%$ na parte aérea, nas plantas com poda total. Nas coletas efetuadas aos 90 e 120 DAT, as plantas que receberam adubação nitrogenada no transplante ou aos 30 DAT tiveram maior massa de parte aérea que as plantas que receberam $\mathrm{N}$ aos 60 ou 90 DAT (Figura 2). Os valores de massa seca da parte aérea obtidos aos 120 DAT (Figura 2) foram superiores ao encontrado por Bregonci et al. (2008) aos 150 dias de aclimatação de mudas micropropagadas da cultivar Gold, e aos valores encontrados por Moreira et al. (2006) aos 90 dias de aclimatização da cultivar Pérola, em diferentes substratos.

Não foram observados efeitos significativos das épocas de aplicação de $\mathrm{N}$ na massa seca de raiz, em nenhuma das datas de coleta (Figura 2). Em todas as épocas de avaliação, a menor massa de raiz ocorreu nas plantas que receberam poda total do sistema radicular. Aos 120 DAT, a massa seca de raiz foi superior nas plantas sem poda, com similaridade entre as que receberam meia-poda e poda total (Figura 2). Estes resultados demonstram que os 120 dias de crescimento após o transplante não foram suficientes para que as plantas que receberam poda total ou parcial do sistema radicular atingissem o mesmo crescimento radicular das plantas que não receberam poda. A massa seca de raiz observada aos 30 DAT foi similar aos valores de mudas micropropagadas da cultivar Gold em tubetes, aos 150 dias de aclimatização (BREGONCI et al., 2008).

Aos 30 DAT, a maior razão raiz:parte aérea ocorreu nas plantas sem poda do sistema radicular, e a menor, nas mudas que receberam poda total (Tabela 1). Nas demais épocas de coleta, a distribuição da biomassa entre parte aérea e raízes ocorreu de forma semelhante nos diferentes tratamentos de poda de raiz. 
Aos 120 DAT, houve maior razão raiz:parte aérea nas plantas que receberam $\mathrm{N}$ aos 90 DAT (Tabela 1), o que demonstra um investimento preferencial na produção de raízes nas plantas que receberam adubação tardia de $\mathrm{N}$, em busca de maior desenvolvimento radicular para aumentar a exploração do solo. Quando alguns nutrientes limitam o crescimento vegetal, em particular o $\mathrm{N}$ e o $\mathrm{P}$, as raízes transformam-se em forte dreno de carboidratos, causando maior limitação ao crescimento da parte aérea do que da raiz, o que aumenta a razão raiz:parte aérea (CLARKSON, 1985).

A análise digital de imagens confirmou seu potencial para mensuração de caracteres radiculares (ARAÚJO et al., 2004), com grande sensibilidade na identificação de diferenças de morfologia radicular das raízes de abacaxi, em resposta aos diferentes tratamentos (Figura 1, Tabela 1), a despeito do grande tempo demandado para espalhamento das raízes e montagem das lâminas para a obtenção das imagens. Os dados de comprimento e área radicular tiveram comportamento muito semelhante, sendo apresentados apenas os dados de área radicular para efeito de síntese. Aos 30 e 60 DAT, as plantas sem poda de raiz tiveram maior área radicular que as plantas com meia-poda e poda total (Figura 2). Aos 90 DAT, as plantas sem poda ou com meia-poda não diferiram entre si, apresentando maior aérea radicular que as plantas com poda total. Aos 120 DAT, as plantas sem poda tiveram maior área de raiz que as plantas com poda. Não foram observados efeitos das épocas de adubação nitrogenada na área radicular, aos 60 e 90 DAT, mas aos 120 DAT as plantas que receberam $\mathrm{N}$ no transplante tiveram maior área radicular que as plantas que receberam $\mathrm{N}$ aos $60 \mathrm{DAT}$ (Figura 2).

Aos 30 e 60 DAT, as plantas sem poda de raiz apresentaram área radicular específica, obtida pela razão entre a área e a massa seca radicular, superior às com meia-poda e poda total, enquanto aos 90 e 120 DAT não houve efeito da poda do sistema radicular na área radicular específica (Tabela 1). Uma elevada área radicular específica indica a obtenção de maior área com menor investimento em massa radicular, ou seja, a produção de raízes mais finas. A menor área radicular específica aos 30 e 60 DAT, das plantas com poda total ou parcial das raízes (Tabela 1 ), indica que as raízes mais novas emitidas pelas plantas que receberam poda do sistema radicular apresentaram maior espessura. A partir dos 60 DAT, as plantas com poda de raízes tiveram aumento da área radicular específica, com a emissão de raízes mais finas a partir da progressiva ramificação do sistema radicular. Por outro lado, as plantas sem poda de raízes tiveram redução da área radicular específica entre os 30 e 90 DAT (Tabela 1), indicando um processo de engros- samento das raízes pré-formadas.

Aos 60 e 90 DAT, não foram observados efeitos das épocas de aplicação de $\mathrm{N}$ na área radicular específica, mas aos 120 DAT as plantas que receberam $\mathrm{N}$ no transplante apresentaram maior área radicular específica que as plantas que receberam $\mathrm{N}$ aos 30 DAT (Tabela 1). Sob condições de baixo suprimento de nutrientes, é comum observar-se uma diminuição do raio radicular, e um sistema radicular com raízes finas poderia ser considerado mais eficiente para absorção de nutrientes, mas não devem ser ignorados outros atributos funcionais de raízes mais grossas em determinadas condições ambientais (EISSENSTAT, 1992). Além disto, o custo de manutenção de raízes finas pode ser maior, pois estas raízes são repostas mais frequentemente (GAHOONIA; NIELSEN, 2004).

\section{Acumulação de $\mathbf{N}$}

As plantas com poda total do sistema radicular apresentaram o menor teor de $\mathrm{N}$ na parte aérea aos 60 DAT, mas inversamente tiveram o maior teor de N na parte aérea aos 120 DAT (Tabela 1). Aos 120 DAT, a maior concentração de N na parte aérea ocorreu nas plantas que receberam $\mathrm{N}$ aos $90 \mathrm{DAT}$ e a menor concentração nas plantas que receberam $\mathrm{N}$ no transplante e aos 30 DAT (Tabela 1). Esse comportamento pode estar relacionado ao efeito de diluição de $\mathrm{N}$ na parte aérea, em virtude do maior crescimento das plantas que receberam $\mathrm{N}$ no transplante e aos 30 DAT (Figura 2). As concentrações de $\mathrm{N}$ na parte aérea foram próximas das encontradas por Paula et al. (1991) em folha diagnóstica da cultivar Pérola, aos 12 meses de idade, que variaram entre $11,0 \mathrm{e}$ 13,6 $\mathrm{mg} \mathrm{g}^{-1}$. Souza (2000) apresenta concentrações de $\mathrm{N}$ entre 15 a $17 \mathrm{mg} \mathrm{g}^{-1}$ na folha diagnóstica como adequadas para o abacaxi. Aos 30 DAT, as plantas que receberam poda total apresentaram o maior teor de $\mathrm{N}$ na raiz, enquanto aos 90 DAT estas plantas tiveram o menor teor de $\mathrm{N}$ na raiz (Tabela 1). Aos 90 DAT, as plantas que receberam $\mathrm{N}$ aos 30 ou aos 60 DAT apresentaram maior teor de $\mathrm{N}$ na raiz que as que receberam $\mathrm{N}$ no transplante. Aos $120 \mathrm{DAT}$, as plantas que receberam $\mathrm{N}$ aos 60 DAT tiveram menor teor de $\mathrm{N}$ na raiz (Tabela 1 ).

A acumulação de $\mathrm{N}$ na parte aérea e raízes das plantas de abacaxi aumentou continuamente durante o período experimental (Figura 3). Ao longo das avaliações, as plantas que receberam poda total apresentaram o menor acúmulo total de $\mathrm{N}$; as plantas que receberam meia-poda, valores intermediários, e as plantas sem poda, os maiores acúmulos de $\mathrm{N}$. Não foram observadas diferenças significativas no conteúdo total de $\mathrm{N}$ em relação à época de aplicação 
do N (Figura 3).

Houve redução contínua dos valores de influxo de $\mathrm{N}$ por unidade de área radicular com o aumento da idade das plantas (Figura 4). Em geral, a taxa de absorção de nutrientes pelas raízes diminui com a ontogenia vegetal, o que pode ser parcialmente atribuído ao menor requerimento vegetal (BARBER, 1984; GAO et al., 1998). Em sistemas radiculares jovens, a taxa de absorção de nutrientes diminui acentuadamente com o envelhecimento das raízes, mas sistemas radiculares mais velhos apresentam pequena taxa de absorção, mas com menor declínio com o tempo (GAO et al., 1998).

Os coeficientes de variação experimental dos influxos de $\mathrm{N}$ foram bem superiores aos da área radicular e do conteúdo de $\mathrm{N}$, refletindo em valores mais amplos da diferença mínima significativa entre tratamentos, estimada pelo teste de Tukey (Figura 4). Elevados valores de variância são comuns nas estimativas das taxas de crescimento pelo método clássico de análise de crescimento vegetal, em particular nas taxas compostas que associam duas grandezas em suas estimativas (ARAÚJO, 2003), como no caso o influxo radicular. Estas elevadas variâncias, muitas vezes, dificultam a identificação de diferenças significativas entre tratamentos na análise estatística das taxas de crescimento (ARAÚJO, 2003). Apesar disto, foi possível identificar diferenças no influxo de $\mathrm{N}$ entre os tratamentos de poda de raízes (Figura 4), inclusive pela utilização de cinco repetições para cada tratamento.

$\mathrm{O}$ influxo de $\mathrm{N}$ nas raízes foi inferior nas plantas sem poda do sistema radicular, no primeiro intervalo de avaliação, entre 30-60 DAT (Figura 4). No intervalo de 60-90 DAT, não houve diferenças significativas no influxo de $\mathrm{N}$ entre os tratamentos de poda, enquanto no intervalo de 90-120 DAT, as plantas que receberam poda total apresentaram maior influxo. Não houve efeito significativo das épocas de aplicação de $\mathrm{N}$ no influxo de $\mathrm{N}$ nas raízes, apesar do maior influxo nas plantas que receberam $\mathrm{N}$ aos 60 DAT, no último intervalo de avaliação (Figura 4).

As plantas que receberam poda total do sistema radicular compensaram sua menor área radicular com maior influxo de $\mathrm{N}$, com raízes com maior atividade de absorção, principalmente por tratar-se de raízes mais jovens. As plantas sem poda radicular, onde foram mantidas as raízes pré-formadas quando do transplante, apresentavam raízes mais finas (Tabela 1), o que também explica sua menor absorção de $\mathrm{N}$ por unidade de área radicular. É comum a observação de relações compensatórias entre influxo de nutrientes e crescimento radicular (ARAÚJO, 2000). Como a acumulação de nutrientes é fortemente de- terminada pela demanda da parte aérea, as diferenças no tamanho do sistema radicular originam aparente diferença na absorção de nutrientes por unidade de sistema radicular (ARAÚJO, 2000).

Os resultados indicam que a prática de poda parcial ou total das raízes pré-formadas das mudas micropropagadas estimulou a emissão inicial de raízes novas com maior espessura, que foram progressivamente sofrendo um processo de ramificação e afinamento (Tabela 1). Entretanto, este investimento em desenvolvimento radicular implicou menor crescimento da parte aérea das plantas com poda de raízes (Figura 1). O menor sistema radicular das plantas com poda de raízes foi parcialmente compensado por maior influxo radicular de N (Figura 4), mas ainda assim resultou em uma menor acumulação de $\mathrm{N}$ ao final do experimento (Figura 3). Desta forma, as raízes pré-formadas das mudas micropropagadas podem assumir papel relevante no estabelecimento da cultura em condições de campo, considerando o lento desenvolvimento do sistema radicular do abacaxizeiro (INFORZATO et al., 1968). Um sistema radicular bem desenvolvido pode também aumentar a tolerância do cultivo ao estresse hídrico (EKERN, 1965) e ao ataque de nematoides (SCHNEIDER et al., 1992). Além disto, o maior crescimento da parte aérea e raízes nas plantas que receberam aplicação do adubo nitrogenado até os 30 dias após o transplante das mudas (Figura 1), demonstra que a aplicação de $\mathrm{N}$ no início do ciclo favorece o desenvolvimento do abacaxizeiro.

A utilização de mudas previamente enraizadas nos plantios comerciais de abacaxizeiro pode propiciar crescimento e desenvolvimento mais rápido das plantas e melhor aproveitamento dos adubos aplicados na fase inicial do cultivo e, consequentemente ,redução no ciclo. Dessa forma, seria possível a indução floral artificial das plantas mais precocemente e a obtenção de frutos com elevado peso em um menor período de tempo, podendo inclusive esta técnica constituir uma ferramenta para se escalonar a produção de frutos em uma exploração comercial de abacaxi. 


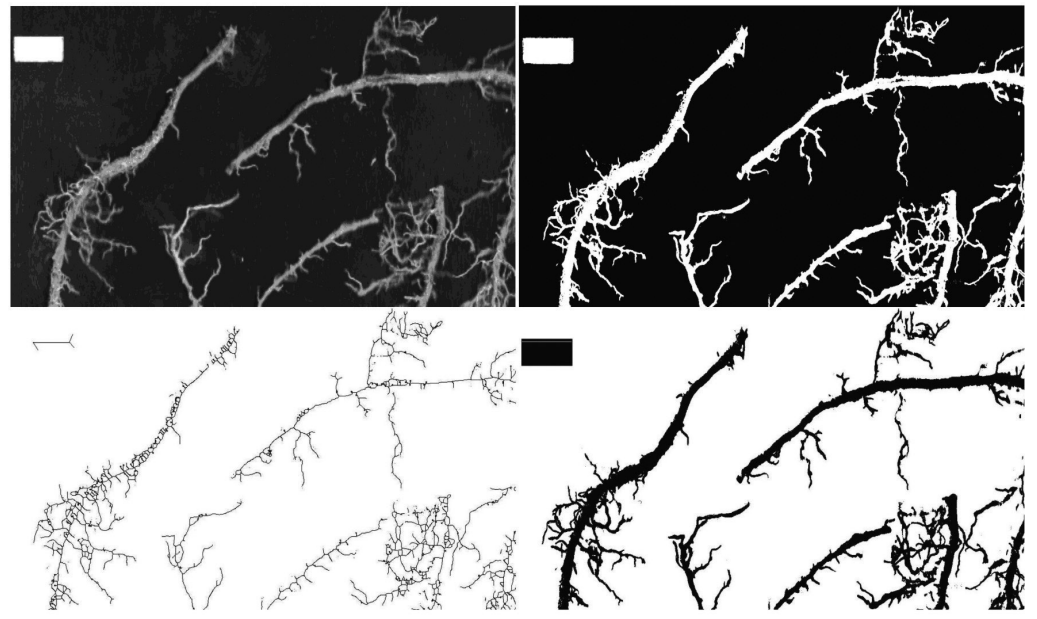

FIGURA 1 - Sequência de processamento de imagens para estimativa da área e comprimento radicular pelo software SIARCS, no sentido horário: imagem digitalizada em tons de cinza com fundo preto; imagem convertida para preto e branco; imagem binarizada para a determinação da área; imagem afinada para a determinação do comprimento. A barra no canto superior esquerdo das imagens representa a escala de $1 \mathrm{~cm}$.

TABELA 1 - Razão de massa entre raiz e parte aérea, e área radicular específica de plantas de abacaxi cultivar Vitória, cultivadas com 3 tratamentos de poda de sistema radicular (sem poda, meiapoda e poda total) e 4 épocas de aplicação do adubo nitrogenado (no transplante, aos 30;60 e 90 dias após o transplante - DAT), em 4 épocas de avaliação (aos 30;60;90 e 120 dias após o transplante - DAT).

\begin{tabular}{|c|c|c|c|c|c|c|c|c|}
\hline \multirow[t]{2}{*}{ Fonte de variação } & \multicolumn{4}{|c|}{ Razão raiz:parte aérea $\left(\mathrm{mg} \mathrm{g}^{-1}\right)$} & \multicolumn{4}{|c|}{ Área radicular específica $\left(\mathrm{cm}^{2} \mathrm{~g}^{-1}\right)$} \\
\hline & 30 DAT & 60 DAT & 90 DAT & 120 DAT & 30 DAT & 60 DAT & 90 DAT & $120 \mathrm{DAT}$ \\
\hline \multicolumn{9}{|l|}{ Poda de raízes } \\
\hline Sem poda & $106 \mathrm{a}$ & 98 & 109 & 92 & $157 \mathrm{a}$ & $145 \mathrm{a}$ & 130 & 126 \\
\hline Meia-poda & $71 \mathrm{~b}$ & 94 & 116 & 85 & $121 \mathrm{~b}$ & $111 \mathrm{~b}$ & 125 & 125 \\
\hline Poda total & $62 \mathrm{~b}$ & 95 & 92 & 77 & $92 \mathrm{~b}$ & $92 \mathrm{~b}$ & 123 & 134 \\
\hline \multicolumn{9}{|c|}{ Época de aplicação de N } \\
\hline No transplante & - & 93 & 98 & $80 \mathrm{~b}$ & - & 124 & 137 & $139 \mathrm{a}$ \\
\hline 30 DAT & - & 99 & 110 & $77 \mathrm{~b}$ & - & 107 & 120 & $116 \mathrm{~b}$ \\
\hline $60 \mathrm{DAT}$ & - & - & 109 & $80 \mathrm{~b}$ & - & - & 121 & $123 a b$ \\
\hline $90 \mathrm{DAT}$ & - & - & - & $102 \mathrm{a}$ & - & - & - & $135 \mathrm{ab}$ \\
\hline \multirow[t]{2}{*}{ Fonte de variação } & \multicolumn{4}{|c|}{ Teor de N na parte aérea $\left(\mathrm{mg} \mathrm{g}^{-1}\right)$} & \multicolumn{4}{|c|}{ Teor de $\mathrm{N}$ na raiz $\left(\mathrm{mg} \mathrm{g}^{-1}\right)$} \\
\hline & $30 \mathrm{DAT}$ & 60 DAT & $90 \mathrm{DAT}$ & $120 \mathrm{DAT}$ & $30 \mathrm{DAT}$ & $60 \mathrm{DAT}$ & 90 DAT & $120 \mathrm{DAT}$ \\
\hline \multicolumn{9}{|l|}{ Poda de raízes } \\
\hline Sem poda & 16,5 & $19,8 \mathrm{a}$ & 21,7 & $20,0 \mathrm{~b}$ & $12,7 \mathrm{~b}$ & 12,0 & $11,5 \mathrm{a}$ & 10,5 \\
\hline Meia-poda & 15,4 & $19,8 \mathrm{a}$ & 20,7 & $19,9 \mathrm{~b}$ & $10,5 \mathrm{~b}$ & 13,0 & $11,7 \mathrm{a}$ & 10,6 \\
\hline Poda total & 12,5 & $16,1 \mathrm{~b}$ & 20,3 & $22,2 \mathrm{a}$ & $14,8 \mathrm{a}$ & 13,5 & $10,3 \mathrm{~b}$ & 10,6 \\
\hline \multicolumn{9}{|c|}{ Época de aplicação de N } \\
\hline No transplante & - & 18,4 & 20,5 & $17,0 \mathrm{c}$ & - & 13,5 & $10,2 \mathrm{~b}$ & $10,8 \mathrm{a}$ \\
\hline 30 DAT & - & 18,7 & 20,0 & $18,2 \mathrm{c}$ & - & 12,2 & $12,5 \mathrm{a}$ & $11,1 \mathrm{a}$ \\
\hline $60 \mathrm{DAT}$ & - & - & 22,2 & $21,9 \mathrm{~b}$ & - & - & $12,5 \mathrm{a}$ & $9,8 \mathrm{~b}$ \\
\hline 90 DAT & - & - & - & $25,8 \mathrm{a}$ & - & - & - & $10,6 \mathrm{ab}$ \\
\hline
\end{tabular}

Médias seguidas pela mesma letra ou desprovidas de letra, dentro da mesma fonte de variação (poda de raízes ou época de aplicação de N), não diferem pelo teste de Tukey, a $5 \%$. 


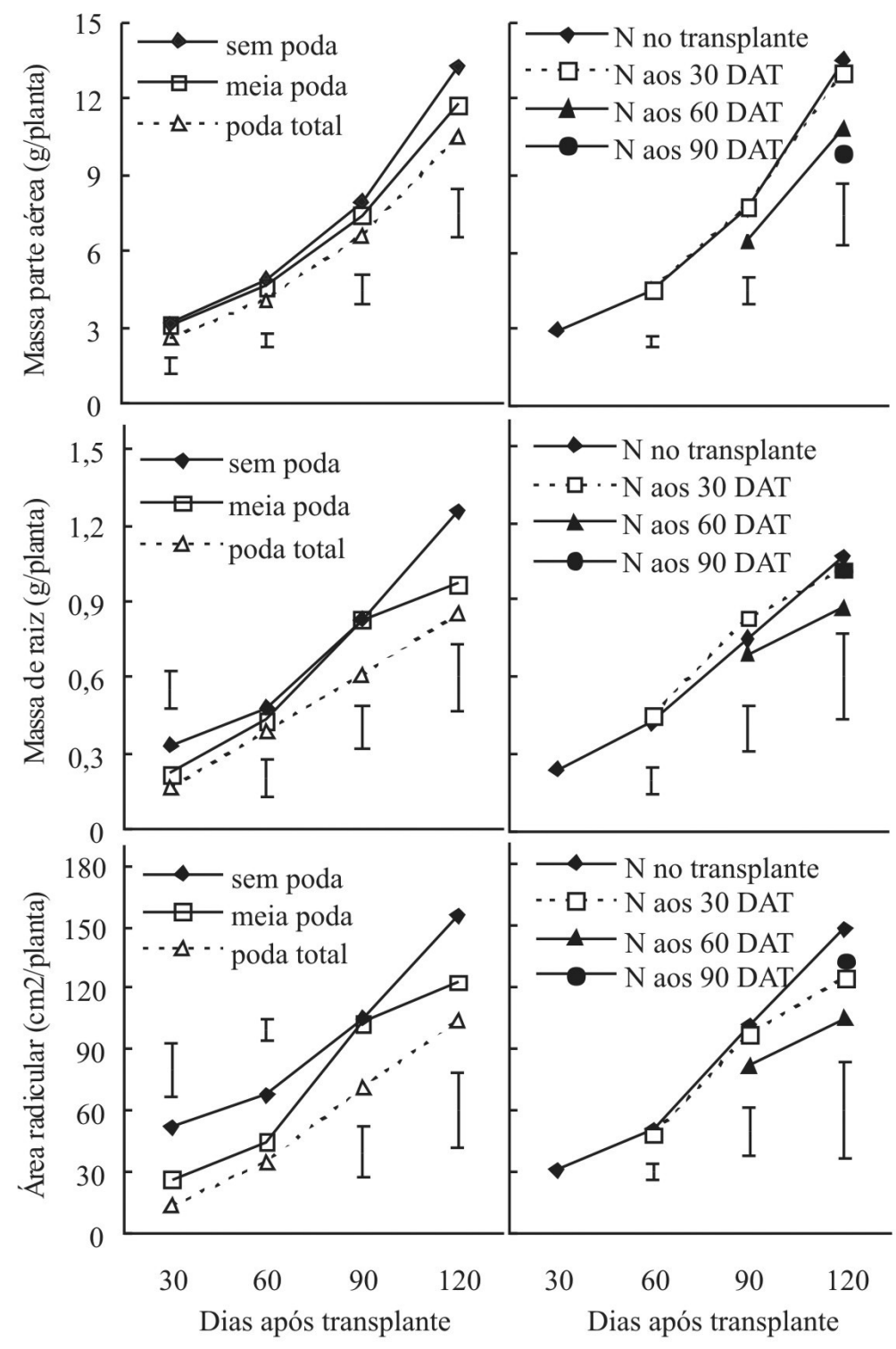

FIGURA 2 - Massa seca de parte aérea, massa seca de raiz e área radicular de plantas de abacaxi cultivar Vitória, em função dos tratamentos de poda do sistema radicular (sem poda, meia-poda e poda total), e em função das épocas de aplicação de N (no transplante, aos 30;60 e 90 dias após o transplante - DAT), em 4 épocas de avaliação (aos 30; 60; 90 e 120 dias após o transplante); as barras verticais representam a diferença mínima significativa do teste de Tukey, a 5\%, e comparam tratamentos dentro de cada época de coleta. Seropédica, 2009. 


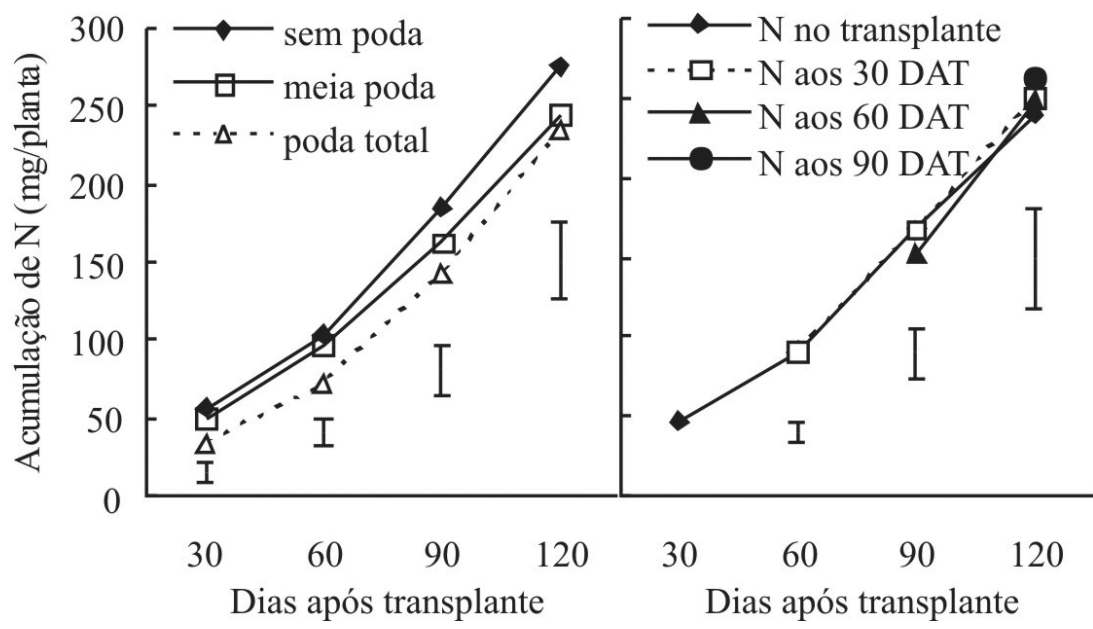

FIGURA 3 - Acumulação de N (parte aérea mais raízes) em plantas de abacaxi cultivar Vitória, em função dos tratamentos de poda do sistema radicular (sem poda, meia-poda e poda total), e em função das épocas de aplicação de N (no transplante, aos 30; 60 e 90 dias após o transplante - DAT), em 4 épocas de avaliação (aos 30; 60; 90 e 120 dias após o transplante); as barras verticais representam a diferença mínima significativa do teste de Tukey, a 5\%, e comparam tratamentos dentro de cada época de coleta. Seropédica, 2009.

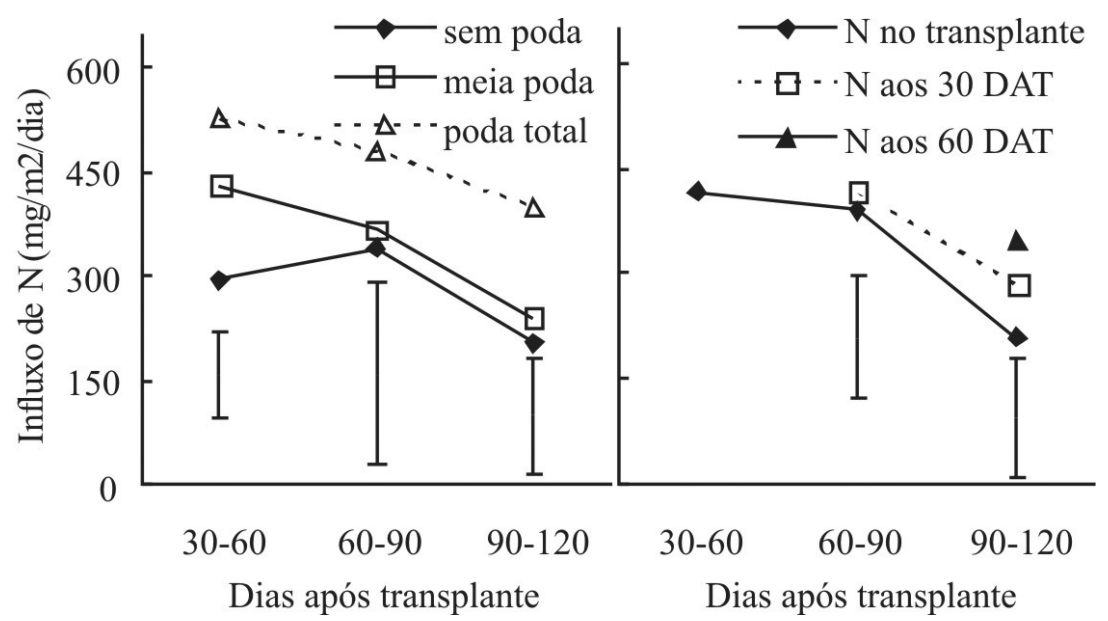

FIGURA 4 - Influxo de N em raízes de plantas de abacaxi cultivar Vitória, em função dos tratamentos de poda do sistema radicular (sem poda, meia-poda e poda total), e em função das épocas de aplicação de N (no transplante, aos 30; 60 e 90 dias após o transplante-DAT), em 3 intervalos entre épocas de avaliação (entre 30 e 60, entre 60 e 90 e entre 90 e 120 dias após o transplante); as barras verticais representam a diferença mínima significativa do teste de Tukey, a 5\%, e comparam tratamentos dentro de cada intervalo entre coletas. Seropédica, 2009. 


\section{CONCLUSÕES}

1-A poda total ou parcial do sistema radicular, no momento do transplante das mudas micropropagadas, reduz a massa seca e a acumulação de $\mathrm{N}$ na parte aérea do abacaxizeiro.

2-A aplicação de N no momento do transplante ou aos 30 dias após o transplante das mudas de abacaxi proporciona maior crescimento da parte aérea, do que a aplicação de $\mathrm{N}$ aos 60 e 90 dias após o transplante.

\section{REFERÊNCIAS}

ARAÚJO, A.P. Analysis of variance of primary data on plant growth analysis. Pesquisa Agropecuária Brasileira, Brasília, v.38, n.1, p.1-10, 2003.

ARAÚJO, A.P. Eficiência vegetal de absorção e utilização de fósforo, com especial referência ao feijoeiro. In: NOVAIS, R.F.; ALVAREZ V., V.H.; SCHAEFER, C.E.G.R. (Ed.). Tópicos em ciência do solo. Viçosa: Sociedade Brasileira de Ciência do Solo, 2000. v.1, p.163-212.

ARAÚJO, A.P.; FERNANDES, A.M.; KUBOTA, F.Y.; BRASIL, F.C.; TEIXEIRA, M.G. Sample size for measurement of root traits on common bean by image analysis. Pesquisa Agropecuária Brasileira, Brasília, v.39, n.4, p.313-318, 2004.

BARBER, S.A. Soil nutrient bioavailability: a mechanistic approach. New York: Wiley-Interscience, 1984. 398p.

BREGONCI, I.S.; SCHMILDT, E.R.; COELHO, R.I.; REIS, E.F.; BRUM, V.J.; SANTOS, J.G. Adubação foliar com macro e micronutrientes no crescimento de mudas micropropagadas do abacaxizeiro cv. Gold [Ananas comosus (L.) Merrill] em diferentes recipientes. Ciência e Agrotecnologia, Lavras, v.32, n.3, p.705-711, 2008.

CLARKSON, D.T. Factors affecting mineral nutrient acquisition by plants. Annual Review of Plant Physiology, Palo Alto, v.36, p.77-115, 1985.

CUNHA, G.A.P.; CABRAL, J.R.S.; MATOS, A.P.; CALDAS, R.C. Avaliação de genótipos de abacaxi resistentes à fusariose em Coração de Maria, Bahia. Magistra, Cruz das Almas, v.19, n.3, p.219-223, 2007.
CUNHA, G.A.P.; REINHARDT, D.H.R. Manejo de mudas de abacaxi. Cruz das Almas: Embrapa Mandioca e Fruticultura, 2004. (Comunicado Técnico, 105).

EISSENSTAT, D.M. Costs and benefits of constructing roots of small diameter. Journal of Plant Nutrition, New York, v.15, p.763-782, 1992.

EKERN, P.C. Evapotranspiration of pineapple in Hawaii. Plant Physiology, Washington, v.40, p.736739, 1965.

EMBRAPA. Empresa Brasileira de Pesquisa Agropecuária. Manual de métodos de análise de solo. 2.ed. Rio de Janeiro: Centro Nacional de Pesquisa de Solos, 1997. 212p.

GAHOONIA, T.S.; NIELSEN, N.E. Root traits as tools for creating phosphorus efficient crop varieties. Plant and Soil, Dordrecht, v.260, p.47-57, 2004.

GAO, S.; PAN, W.L.; KOENIG, R.T. Integrated root system age in relation to plant nutrient uptake activity. Agronomy Journal, Madison, v.90, p.505510, 1998.

GUERRA, M.P.; DAL VESCO, L.L.; PESCADOR, R.; SCHUELTER, A.R.; NODARI, R.O. Estabelecimento de um protocolo regenerativo para a micropropagação do abacaxizeiro. Pesquisa Agropecuária Brasileira, Brasília, v.34, n.9, p.1557-1563, 1999.

IBGE. Instituto Brasileiro de Geografia e Estatística. Censo agropecuário 2006. Disponível em: $<$ http:// www.ibge.gov.br/home/estatistica/economia/agropecuaria/censoagro/brasil_2006>. Acesso em: 20 out. 2009.

IBGE. Instituto Brasileiro de Geografia e Estatística. Produção agrícola municipal. Disponível em: $<$ http://www.sidra.ibge.gov.br $>$. Acesso em: 20 jul. 2010 .

INFORZATO, R.; GIACOMELLI, E.J.; ROCHELLE, L.A. Sistema radicular do abacaxizeiro, aos 4, 8 e 12 meses, plantado no início da estação sêca, em solo Latosol Vermelho Escuro-Orto. Bragantia, Campinas, v.27, p.135-141, 1968. 
MOREIRA, A.M.; CARVALHO, J.G.; PASQUAL, M.; FRÁGUAS, C.B.; SILVA, A.B. Efeito de substratos na aclimatação de mudas micropropagadas de abacaxizeiro cv. Pérola. Ciência e Agrotecnologia, Lavras, v.30, n.5, p.875-879, 2006.

PAULA, M.B.; CARVALHO, V.D.; NOGUEIRA, F.D.; SOUZA, L.F.S. Efeito da calagem, potássio e nitrogênio na produção e qualidade do fruto do abacaxizeiro. Pesquisa Agropecuária Brasileira, Brasília, v.26, n.9, p.1337-1343, 1991.

PY, C.; LACOEUILHE, J.J.; TEISSON, C. The pineapple: cultivation and uses. Paris: Maisonneuve et Larose, 1987. 568p.

SAN JOSÉ; J.; MONTES, R.; CABRERA-BISBAL, $\mathrm{E}$. Nitrogen budget in a pineapple crop growing in the Orinoco lowlands. Communications in Soil Science and Plant Analysis, New York, v.38, n.3/4, p.423-447, 2007.

SCHNEIDER, R.C.; ZHANG, J.; ANDERS, M.M.; BARTHOLOMEW, D.P.; CASWELL-CHEN, E.P. Nematicide efficacy, root growth, and fruit yield in drip-irrigated pineapple parasitized by Rotylenchulus reniformis. Journal of Nematology, College Park, v.24, n.4, p.540-547, 1992.
SOUZA, L.F.S. Adubação. In: REINHARDT, D.H.; SOUZA, L.F.S.; CABRAL, J.R.S. (Org.). Abacaxi produção: aspectos técnicos. Brasília: Embrapa Comunicação para Transferência de Tecnologia, 2000. p.30-34.

SPIRONELLO, A.; QUAGGIO, J.A.; TEIXEIRA, L.A.J.; FURLANI, P.R.; SIGRIST, J.M. M. Pineapple yield and fruit quality affected by NPK fertilization in a tropical soil. Revista Brasileira de Fruticultura, Jaboticabal, v.26, n.1, p.155-159, 2004.

TEIXEIRA, L.A.J.; SPIRONELLO, A.; FURLANI, P.R.; SIGRIST, J.M.M. Parcelamento da adubação NPK em abacaxizeiro. Revista Brasileira de Fruticultura, Jaboticabal, v.24, n.1, p.219-224, 2002.

VELOSO, C.A.C.; OEIRAS, A.H.L.; CARVALHO, E.J.M.; SOUZA, F.R.S. Resposta do abacaxizeiro à adição de nitrogênio, potássio e calcário em Latossolo Amarelo do Nordeste Paraense. Revista Brasileira de Fruticultura, Jaboticabal, v.23, n.2, p.396-402, 2001.

VENTURA, J.A.; CABRAL, J.R.S.; MATOS, A.P.; COSTA, H. 'Vitória' nova cultivar de abacaxi resistente à fusariose. Vitória: Incaper, 2006. (Documentos, 148). 